\title{
Medical engagement in organisation-wide safety and quality-improvement programmes: experience in the UK Safer Patients Initiative
}

\author{
Anam Parand, Susan Burnett, Jonathan Benn, Sandra Iskander, Anna Pinto, \\ Charles Vincent
}

Imperial College London, London, UK

\section{Correspondence to}

Miss Anam Parand, Department of Surgery and Cancer, Imperial College London, Rm 503, 5th Floor Wright Fleming Building, St Mary's Campus, Norfolk Place, London W2 1PG, UK: a.parand@imperial.ac.uk

Accepted 4 March 2010 Published Online First 9 June 2010

\begin{abstract}
Objectives To identify factors affecting doctors' engagement with the Safer Patients Initiative (SPI). Design Qualitative interview study.

Setting Four organisations participating in phase 1 of the SPI programme, from four different geographical locations in the UK.

Participants 34 staff members, comprising senior executive/management leads involved in the SPI programme, the principal SPI programme coordinator and the operational leads in each of the SPI clinical work areas.
\end{abstract}

Main outcome measures Staff perceptions of issues affecting medical engagement with SPI, identified in the interviews.

Results Qualitative analysis identified seven factors that were reported to affect medical engagement with the SPI programme: (1) Organisation Track Record in OSI, (2) Resource Availability \& Allocation, (3) Perceptions of the purpose of SPI, (4) Evidence of Efficacy of Programme, (5) External Expertise, (6) Local Programme Champions and (7) Managers Involvement. Specific barriers and general enabling strategies were identified and described for each factor, based upon participants' experiences.

Conclusions Medical engagement is a complex technical, socio-political and motivational issue that is underpinned by a series of inter-related factors associated with the organisational context, the design of improvement programmes and how they are implemented and promoted. Healthcare organisations planning to embark on safety and quality-improvement programmes may benefit from systematically addressing the core themes identified by this study, in order to promote optimal medical engagement.

\section{INTRODUCTION}

The safety and quality of care is the core daily concern of every clinician striving for improved patient outcomes. Recently, improving safety and quality has become the focus of large-scale organisation-wide programmes that go beyond the patient-clinician interface to address the underlying care system including cultural and organisational issues. ${ }^{1}$ In so doing, they involve a broad spectrum of the healthcare work force, including senior managers, governance and corporate functions, doctors, nurses and allied health professionals. The engagement of doctors in particular is seen by many, researchers and field experts alike, to be an essential factor for the success of such programmes. ${ }^{2-4}$
In the UK, there have been calls for a transition from clinical engagement to clinical leadership. ${ }^{5} 6$ In 2008, the NHS Institute for Innovation and Improvement commissioned projects with the Academy of Medical Royal Colleges to review the engagement of clinicians in leadership to provide a framework to increase doctor involvement and influence organisational performance. ${ }^{78}$

Despite the recognised importance of medical engagement in organisation-wide safety and quality improvement, it is often described as a challenge to achieve with solutions "largely lacking' and as a problematic issue that requires attention. ${ }^{29}$ Furthermore, there is limited research evidence detailing the factors that affect doctors' engagement in such initiatives.

This paper presents findings concerning the factors that are reported to affect engagement of doctors in an organisation-wide safety improvement programme from a qualitative research study of the first phase of the UK Safer Patients Initiative (SPI).

\section{Safer Patients Initiative}

Funded by the UK Health Foundation, the SPI was developed by the Institute of Healthcare Improvement (IHI) and was piloted with four UK NHS organisations in its first phase (2004-2006) and applied at a further 20 in its second phase (2007-2008). ${ }^{10}{ }^{11}$ Designed to achieve improvements in patient safety, SPI attempts to make changes at an organisational level and in front line care processes within four clinical areas through implementing a number of clinical working practices with continuous quality improvement and process measurement techniques. ${ }^{12} 13$

\section{METHODS}

\section{Setting}

Interviews were carried out across four organisations participating in phase 1 of SPI from different geographical locations in the UK: England $(n=9)$, Northern Ireland $(n=7)$, Scotland $(n=8)$ and Wales $(n=10)$.

\section{Participants}

A purposive sampling strategy was employed and each organisation comprised of those who were directly involved in leading SPI within their organisations, including all four Chief Executives and Patient Safety/Governance leads. Four of the interviewees were doctors, five were pharmacists, and 14 were practising nurses. See table 1 for participant demographics. 
Table 1 Characteristics of interviewees

\begin{tabular}{|c|c|c|c|}
\hline Organisation & $\begin{array}{l}\text { Interviewee } \\
\text { No }\end{array}$ & Sex & Occupation \\
\hline \multirow[t]{10}{*}{1} & 1 & M & Nurse \\
\hline & 2 & $\mathrm{~F}$ & Nurse \\
\hline & 3 & M & Nurse \\
\hline & 4 & M & Doctor \\
\hline & 5 & $\mathrm{~F}$ & Nurse \\
\hline & 6 & $\mathrm{~F}$ & Nurse \\
\hline & 7 & $\mathrm{~F}$ & Nurse \\
\hline & 8 & $\mathrm{~F}$ & Patient safety/governance lead \\
\hline & 9 & M & CEO \\
\hline & 10 & M & Pharmacist \\
\hline \multirow[t]{9}{*}{2} & 11 & M & Doctor \\
\hline & 12 & $\mathrm{~F}$ & Nurse \\
\hline & 13 & $\mathrm{~F}$ & Pharmacist \\
\hline & 14 & $\mathrm{~F}$ & Nurse \\
\hline & 15 & $\mathrm{~F}$ & Patient safety/governance lead \\
\hline & 16 & $\mathrm{~F}$ & Pharmacist \\
\hline & 17 & M & Doctor \\
\hline & 18 & M & CEO \\
\hline & 19 & $\mathrm{~F}$ & Nurse \\
\hline \multirow[t]{7}{*}{3} & 20 & $\mathrm{~F}$ & Nurse \\
\hline & 21 & $M$ & CEO \\
\hline & 22 & M & Patient safety/governance lead \\
\hline & 23 & $\mathrm{~F}$ & Nurse \\
\hline & 24 & $\mathrm{~F}$ & Patient safety/governance lead \\
\hline & 25 & M & Patient safety/governance lead \\
\hline & 26 & $\mathrm{~F}$ & Pharmacist \\
\hline \multirow[t]{8}{*}{4} & 27 & $\mathrm{~F}$ & Nurse \\
\hline & 28 & M & Doctor \\
\hline & 29 & $\mathrm{~F}$ & Patient safety/governance lead \\
\hline & 30 & $\mathrm{~F}$ & Nurse \\
\hline & 31 & $\mathrm{~F}$ & Nurse \\
\hline & 32 & M & Pharmacist \\
\hline & 33 & M & CEO \\
\hline & 34 & $\mathrm{~F}$ & Patient safety/governance lead \\
\hline
\end{tabular}

\section{Interviews}

Thirty-four semistructured individual interviews, lasting between 45 and $60 \mathrm{~min}$, were conducted between August and December 2007, at which time the organisations were receiving continued development support from SPI resources 12 months after intensive external expert guidance from Institute for Healthcare Improvement. Participants were presented with a research information sheet and briefed on the confidentiality and anonymity of any information provided. Signed consent was obtained for audio-recording the interviews for later transcription and analysis. A standardised semistructured interview topic guide was used by the two interviewers.

This study forms part of a larger series of studies addressing a number of issues with medical engagement forming one avenue of enquiry. ${ }^{14-16}$ The standard interview topic guide covered a range of issues important to the broader research aims but addressed the areas of staff engagement and programme barriers using the following prompts:

- How did you ensure the engagement of front line staff in the SPI programme?

- How did you maintain motivation and commitment to SPI during the programme?

- What were the more challenging barriers to the success of SPI within your organisation, and what remedial actions were necessary:

- in terms of running SPI locally?
- in terms of achieving positive outcomes?

In the interests of achieving saturation of information and in line with established qualitative research methodology, ${ }^{17}$ the interviewers used expansive questioning to explore specific perceptions of factors affecting medical engagement and the strategies used to challenge them.

\section{Data analysis}

Qualitative interviews were transcribed by professional transcribers. Qualitative analysis was performed using the constant comparative technique with the aid of NVIVO (version 8) qualitative analysis software. ${ }^{17} 18$ Two researchers were primarily responsible for the qualitative analysis with regular input from three other researchers with diverse backgrounds to ensure multiple perspectives and consistency in coding. For analysis purposes, medical engagement was defined as references to doctors displaying active interest or a positive role of involvement within the programme. Preliminary detailed open-coding was undertaken before codes were combined into broader thematic categories. As part of this phase, each transcript was content-analysed for direct and indirect references to medical engagement. Axial coding was performed to group and relate the emerging themes according to their influence on medical engagement. Theme saturation was achieved, and iterative refinement of a model of positive and negative dimensions was undertaken through discussion among the research team.

\section{RESULTS}

From the accounts given by the interviewees, seven factors were identified to affect the level of medical engagement with the SPI programme. Table 2 displays these factors along with their related directional dimensions, which are split into barriers and enablers. The quotations are examples representative of consistent themes that emerged from the analysis across all interviews.

\section{The organisation's track record in quality and safety improvement \\ Enablers}

The organisation's previous approach to quality and safety was indicated as a factor that affected medical engagement in SPI. Where the programme was seen as continuous improvement, medical engagement was more active.

...the SPI thing is, is not going away, and I think maybe that's
made the difference [to medical engagement]. (Interviewee 16)

\section{Barriers}

Those perceiving SPI to be a temporary project with a definitive timeline did not involve themselves as extensively. There was a sense that programme fatigue from repeated involvement in initiatives would diminish the likelihood of doctors engaging with a new programme:

I think for some clinicians and because probably [organisation $\mathrm{x}$ ] had quite a tradition of striving for quality accreditations and things...it was perceived that this was just yet another award that the trust was going for. (Interviewee 23)

\section{Resource availability and allocation} Enablers

Protecting the time doctors were allocated to spend on the programme by managers was thought of as something that would have helped integrate doctors into the initiative: 
Table 2 Factors affecting medical engagement with the Safer Patients Initiative

\begin{tabular}{|c|c|c|}
\hline Barriers & Factors affecting medical engagement & Enablers \\
\hline Programme implemented or viewed as a temporary project & 1. Quality improvement track record & Doctors previously tried to change practices \\
\hline Initiative overkill & & $\begin{array}{l}\text { Programme implemented or viewed as a continuous } \\
\text { improvement process }\end{array}$ \\
\hline $\begin{array}{l}\text { Doctors' work commitments preventing time to be spent on } \\
\text { programme-related work }\end{array}$ & 2. Resource allocation & Time is allocated to programme work \\
\hline \multicolumn{3}{|l|}{ Programme work perceived by doctors to be more or extra work } \\
\hline \multicolumn{3}{|l|}{ Doctors' perception that there is not enough time } \\
\hline Doctors' perception of blame apportioned by programme & 3. Perceptions of the purpose of SPI & Doctors' perceptions of genuine purpose of Safer Patients \\
\hline Doctors' belief of responsibility to stick with their best practices & & Initiative to improve safety of care \\
\hline \multicolumn{3}{|l|}{ Usually not carried out by medical staff } \\
\hline \multicolumn{3}{|l|}{ Poor communication of purpose of Safer Patients Initiative } \\
\hline Lack of scientific evidence on programme components & 4. Evidence of efficacy & $\begin{array}{l}\text { Demonstration of Institute for Healthcare Improvement gathered } \\
\text { information }\end{array}$ \\
\hline \multirow[t]{2}{*}{ Previous medical training } & & Demonstration of local evidence \\
\hline & & Local feedback \\
\hline None reported & 5. External expertise & $\begin{array}{l}\text { External experts (Institute for Healthcare Improvement) providing } \\
\text { 'credibility' }\end{array}$ \\
\hline Poor relationship/rapport between champions and doctors & 6. Local programme champions & Good relationship/rapport between champions and doctors \\
\hline \multirow[t]{2}{*}{ Not involving doctors champions from the start of the programme } & & Senior medical champions leading by example \\
\hline & & Involving doctors champions from the start of the programme \\
\hline \multirow[t]{2}{*}{ None reported } & 7. Managerial involvement & Involving managers to increase doctor engagement \\
\hline & & Good relationship between Management and doctors \\
\hline
\end{tabular}

...to get totally involved in things it's very difficult unless ... they're actually released. Their manager tells them, yes, you have to get somebody in, you have to attend. (Interviewee 26)

\section{Barriers}

In contrast, limited allocation of resources created difficulties for doctors' with a number of interviewees saying that the reason doctors did not engage with SPI was that the changes were seen as extra work in addition to their current job.

\section{Perceptions of the purpose of SPI Enablers}

The profile of SPI in the organisation and the way it was introduced contributed to different perceptions of its purpose and hence different degrees of participation by doctors. Doctors who viewed the programme as a genuine attempt to improve the safety of care became actively involved in SPI at an early stage.

\section{Barriers}

Poor communication about the SPI methods, such as 'care bundles,' led to resistance with doctors feeling accused of not carrying out the best clinical practice as promoted by the programme:

...this is just...medical culture that is centuries old, autonomy,

and...'I'm not going to listen or change my practice because

somebody else is telling me.' (Interviewee 11)

Some respondents additionally reported doctors were not willing to change because they were confident that they were already adhering to best practice or because it was considered irrelevant to their duties.

\section{Evidence of efficacy}

Enablers

Successful strategies were employed to provide doctors with local evidence and the evidence base available through IHI. This was reported to increase doctors' compliance with the recommended programme practices.

\section{Barriers}

Interviewees noted that some doctors' reluctance to become fully involved was influenced by their issues with the scientific evidence for elements of the care bundles and the "plan, do, study, act' (PDSA) approach to change as opposed to clinical audit and evaluative research:

Oh my God doctors having heart failure...doctors really struggle with the idea of quick and dirty ... they're trained in ensuring that statistical significance is applied at all appropriate times, which is normally interpreted as at all times. (Interviewee 7)

\section{External expertise}

Enabler

The credibility of the doctors at IHI delivering the programme clearly helped to gain clinical engagement locally, particularly due to their practical experience of the changes:

one of the key strengths of the SPI is you've got these international gurus. I could come in . . and say, hey doctor, there's a really good way that you could do this and they'll go, yeah sod off... whereas a doctor comes in from the IHI and says, not only is it a good a theory I've done it...that doctor is much more likely therefore to take on that approach. (Interviewee 7)

\section{Local programme champions}

Enablers

Local champions for each clinical area affected by SPI were recruited from the outset and attended the IHI learning events. Interviewees described their important role in leading change or in quietly helping to spread awareness.

Many interviewees described having senior medical champions as a real facilitator of medical engagement because they offered 'clout' and led by example. Additionally, the rapport between champions and their medical colleagues was believed to have had an impact on the ease of getting doctors onboard. 
...I had worked with them [lead clinicians] before I had maybe a better relationship than other people ... So I would have been able to take things through... and get agreement...without a formal meeting as such... (Interviewee 20)

\section{Barriers}

Conversely, the relationship between champions and doctors was noted as a negative for those who did not hold or had not yet built rapport.

Now there was a great disadvantage to me coming to the organisation, because it takes years to build up relationships with some of the consultants. (Interviewee 10)

Interviewees suggested that the timing of involving the doctors as champions within the initiative played an important role in their engagement. Above all, their recommendation was to involve doctors in the programme from the start and that not doing so can be a barrier to their future engagement.

\section{Management involvement \\ Enablers}

Commitment at executive level was often reported to positively influence medical engagement.

...because it became a priority at Trust Board level, I think... that some of the [doctors] woke up to, to it. (Interviewee 16)

One of the most common strategies to improve medical commitment to the programme was that of involving the doctors that are in managerial positions.

Good existing relationships between managers and doctors were seen as important in the propensity for doctors to become involved in the programme.

\section{DISCUSSION}

This study emphasises that medical engagement in improvement programmes is a complex socio-political and motivational issue that is underpinned by a series of inter-related factors associated with the organisational context, the design of improvement programmes and how they are implemented and promoted. An organisation's track record and overall approach to quality and safety improvement are important in influencing a doctor's motivation to become engaged. Where this record is one of multiple initiatives over many years with little visible commitment to ongoing support, 'initiative overkill' and decreased buy-in results.

Doctor attitudes towards the programme can be dependent on how the aims of the programme are communicated and perceived. Where new ways of working in SPI were seen as a criticism of existing medical practice, doctors negatively viewed the changes as a reflection on their previous care provision, as found by two other studies. ${ }^{2} 19$ Other authors have also found attitude to be a factor that influences medical engagement, ${ }^{20}$ and that the concept of doctor buy-in is more likely if the stated purpose is important to the doctors. ${ }^{2}$

Evidence of efficacy was required for many doctors to become engaged with SPI, including the approach to change using PDSA cycles and 'care bundles.' Both approaches challenged existing medical thinking on how to implement safe healthcare. Neale et al recommend that to engage clinicians in promoting quality and safety would call for a change of learning and attitudes and behaviours that can be formulated within the training structure. ${ }^{9}$

The impact of resource constraints such as extra work ${ }^{19}$ and time $^{4}$ mentioned in the literature was also pointed out by interviewees. One of the main roles of managers was seen as allocating resources, facilitating doctors' involvement and maintaining good working relationships. Ham recommends that doctors require time to establish new practices, and managers are responsible for provision of resources and should work closely with clinical champions. ${ }^{21}$

Programme champions were identified as agents of change, with acknowledgement of doctors' higher regard for the views of their medical peers when faced with change in their clinical practices. Interviewees reported champion-doctor interactions to either facilitate or inhibit doctor engagement, highlighting the importance of selecting people for this role who have good rapport with doctors.

In summary, the findings from this and other related studies suggest that medical engagement in safety and quality improvement relies on seven core themes each of which should be considered and addressed before organisations embark on qualityimprovement programmes. These are summarised in box 1 .

\section{Limitations}

The small sample size and that it comprised significantly more nurses than doctors is acknowledged as a limitation of this study. However, the sample represented all those involved in leading the first phase of SPI in the UK. As with all qualitative research, the challenge is to develop theory that adequately represents or is grounded in the underlying data. Many factors relating to medical engagement in this study were found to be conceptually inter-related. In practical terms, satisfying one

\section{Box 1 Seven core themes to address for medical engagement}

- The organisation's track record in quality improvementwhere there is a history of numerous short-term improvement programmes, organisations should consider ways of generating and maintaining enthusiasm for new programmes and emphasise their novelty.

- Resource availability and allocation-managers must take practical steps (such as identifying funding and making arrangements to reduce clinical sessions) to ensure that medical staff have the time they need to be actively involved.

- Perceptions of the purpose of the initiative-explanations of the purpose of programmes should be phrased in terms reflecting the priorities and concerns of clinicians, and assurance of a no-blame initiative will help.

- Evidence of efficacy-organisations should be aware that implementing quality programmes without a strong evidence base will lead to difficulties in engaging clinicians and that offering local evidence will go some way to diminish doubts held.

- External expertise-where external expertise is not an inherent part of a programme, organisations could consider ways of achieving the same results-for example, by seeking some form of support from external sources.

- Local programme champions - the choice of clinical leads is crucial, with the key consideration being the leader's credibility with other clinicians, rather than with managers.

- Management Involvement-if a history of strong managerdoctor relationship does not exist, it may be appropriate to consider ways of engaging managers in these programmes, who in turn are in a position to support clinical engagement. 
criterion, such as managerial involvement, may in turn satisfy other enablers such as satisfactory resource allocation.

\section{Conclusion}

This study has presented the factors that were perceived to have affected the involvement of doctors in an organisation-wide safety and quality-improvement programme. Many of the reported enabling strategies can be used as pre-emptive measures to facilitate doctor engagement from the outset of a quality and safety programme.

From a practical viewpoint, the factors that have been reported here can be divided into those that have a clear implication of what to change within a planned intervention (eg, programme continuity) and those that appear impossible to prepare for (eg, organisational track record). It is therefore advisable that healthcare leaders pay attention to those areas within their control, and other factors may be changed through the delivery of the programme.

Future work is required to examine whether these factors vary across different types of initiatives, across different institutions, with a higher number of organisations and a sample that is made up wholly of doctors. Other work of interest would demonstrate what value medical engagement brings and draw out more salient detail of certain themes discussed in this paper.

Acknowledgements The authors gratefully acknowledge the contributions of the healthcare professionals who agreed to be interviewed as part of this study.

Funding This work was supported by funding from the Health Foundation and the National Institute for Health Research.

Competing interests None.

Ethics approval The National Research Ethics Service (NRES) approved this research as an Audit/Evaluation.

Provenance and peer review Not commissioned; externally peer reviewed.

\section{REFERENCES}

1. Ovretveit $\mathbf{J}$, Bate $P$, Cleary $P$, et al. Quality collaboratives: lessons from research. Qual Saf Health Care 2002;11:345-51.

2. Gosfield AG. Finding common cause in quality: confronting the physician engagement challenge. Physician Exec 2008;34:26-31.
3. Bowns IR, McNulty T. Reengineering Leicester Royal Infirmary: an independent evaluation of implementation and impact. Sheffield: School of Health and Related Research, University of Sheffield, 1999.

4. Reinertsen JL, Gosfield AG, Rupp W, et al. Engaging physicians in a shared quality agenda. IHI Innovation Series White Paper. Cambridge, MA: Institute for Healthcare Improvement, 2007:1-48.

5. Carruthers I. Department of health clinical leadership health summit, 2007. http:// www.dh.gov.uk/en/Managingyourorganisation/Healthreform/DH_073231 (accessed 20 Jul 2009).

6. Darzi A. High quality care for all: NHS Next Stage Review final report: Department of Health report, 2008:1-84

7. Hamilton P, Spurgeon P, Clark J, et al. Engaging doctors: can doctors influence organisational performance? Enhancing engagement in medical leadership. Coventry: NHS Institute for Innovation and Improvement, 2008.

8. Dickinson $\mathbf{H}$, Ham C. Engaging doctors in leadership: review of the literature. Coventry: NHS Institute for Innovation and Improvement / Health Services Management Centre, 2008.

9. Neale G, Vincent $C$, Darzi AS. The problem of engaging hospital doctors in promoting safety and quality in clinical care. J R Soc Health 2007;127:87-94.

10. HF. The safer patients initiative, 2009. http://www.health.org.uk/current work/ demonstration_projects/safer_patients_1.html\#chapter5 (accessed 20 Jul 2009)

11. IHI. The breakthrough series: IHI's collaborative model for achieving breakthrough improvement. Diabetes Spectr 2004:97-101.

12. Langley GJ, Nolan KM, Nolan TW, et al. The improvement guide: a practical approach to enhancing organizational performance. San Francisco, CA: Jossey-Bass Publishers, 1966

13. Carey RG. Improving healthcare with control charts: basic and advanced SPC methods and case studies. Milwaukee, WI: ASO Quality Press, 2003.

14. Benn J, Burnett S, Parand A, et al. Perceptions of the impact of a large-scale collaborative improvement programme: experience in the UK safer patients initiative. J Eval Clin Pract 2009;15:524-40.

15. Benn J, Burnett S, Parand A, et al. Studying large-scale programmes to improve patient safety across multiple organisations: Challenges for research. Soc Sci Med 2009;69:1767-76.

16. Burnett S, Benn J, Pinto A, et al. Organisational Readiness: Exploring the preconditions for success in organisation-wide patient safety improvement programmes. Qual Saf Health Care 2010;19:313-317.

17. Strauss A, Corbin J. Basics of qualitative research: grounded theory procedures and techniques. Newbury Park, CA: Sage, 1990.

18. Glaser B, Stauss A. The discovery of grounded theory: strategies for qualitative research. Chicago: Aldine, 1977.

19. Shekelle PG. Why don't physicians enthusiastically support quality improvement programmes? [Editorial]. Qual Saf Health Care 2002;11:6.

20. Alexander JA, Hearld LR, Jiang $\mathrm{HJ}$, et al. Increasing the relevance of research to health care managers: hospital CEO imperatives for improving quality and lowering costs. Health Care Manage Rev 2007;32:150-9.

21. Ham C. Improving the performance of health services: the role of clinical leadership. Lancet 2003;361:1979-80. 